\title{
EFFECT OF CULTURE MEDIUM ON BIOCALCIFICATION BY PSEUDOMONAS PUTIDA, LYSINIBACILLUS SPHAERICUS AND BACILLUS SUBTILIS
}

\author{
Márcia Aiko Shirakawa $^{1 *}$, Maria Alba Cincotto ${ }^{1}$, Daniel Atencio ${ }^{2}$, Christine C.Gaylarde ${ }^{3}$, Vanderley M. John ${ }^{1}$ \\ ${ }^{1}$ Departamento de Engenharia de Construção Civil, Escola Politécnica, Universidade de São Paulo, São Paulo, SP, Brasil; \\ ${ }^{2}$ Departamento de Mineralogia e Geotectônica, Instituto de Geociências, Universidade de São Paulo, São Paulo, SP, Brasil; \\ ${ }^{3}$ University of Portsmouth, Microbiology Research Laboratory, School of Pharmacy and Biomedical Sciences, Portsmouth, UK.
}

Submitted: June 05, 2009; Returned to authors for corrections: June 10, 2010; Approved: January 13, 2011.

\begin{abstract}
The objective of this study is to investigate the efficiency of calcium carbonate bioprecipitation by Lysinibacillus sphaericus, Bacillus subtilis and Pseudomonas putida, obtained from the Coleção de Culturas do Instituto Nacional de Controle de Qualidade em Saúde (INCQS), as a first step in determining their potential to protect building materials against water uptake. Two culture media were studied: modified B4 containing calcium acetate and 295 with calcium chloride. Calcium consumption in the two media after incubation with and without the bacterial inoculum was determined by atomic absorption analysis. Modified B4 gave the best results and in this medium Pseudomonas putida INQCS 113 produced the highest calcium carbonate precipitation, followed by Lysinibacillus sphaericus INQCS 414; the lowest precipitation was produced by Bacillus subtilis INQCS 328. In this culture medium XRD analysis showed that Pseudomonas putida and Bacillus subtilis precipitated calcite and vaterite polymorphs while Lysinibacillus sphaericus produced only vaterite. The shape and size of the crystals were affected by culture medium, bacterial strain and culture conditions, static or shaken. In conclusion, of the three strains Pseudomonas putida INQCS 113 in modified B4 medium gave the best results precipitating $96 \%$ of the calcium, this strain thus has good potential for use on building materials.
\end{abstract}

Key words: Pseudomonas putida, Lysinibacillus sphaericus, Bacillus subtilis, calcium carbonate, biocalcification.

\section{INTRODUCTION}

In nature, biomineralization is the process by which living organisms precipitate inorganic minerals in the form of skeletons, shells, teeth, etc (18). According to Lowenstam (9), two different process of mineral formation can be distinguished. The first occurs in numerous animals as an "organic matrix mediated process". The second, exemplified by some bacterial species and algae, is characterized by bulk extracellular and/or intracellular mineral formation. 
Biocalcification, or specifically the bioprecipitation of calcium carbonate, is an example of this phenomenon well described in the literature $(1,2,7,12,13,14,19)$. The reaction is widely distributed in soil, freshwater and marine environments. Boquet et al (1) isolated 210 microorganisms that were able to precipitate calcium carbonate in culture media, including, among others: Salmonella spp., Azotobacter spp., several Bacillus species, Pseudomonas aeruginosa, Serratia spp. and Staphylococcus aureus.

The main research on biocalcification is related to restoration of limestone on historic buildings $(8,15,16)$. However, its potential application in building and construction is much wider, including soil stabilization $(3,17)$, mortar and concrete surface protection $(4,5)$ and concrete repair (11). Various microorganisms have been tested, but as different research groups use different conditions and culture media it is difficult to compare the results (6). Within the wide range of microorganisms, human pathogenic bacteria obviously cannot be considered for application on materials.

One of the most acceptable hypotheses for calcium carbonate precipitation is that calcium ions are not used by microbial metabolism, and hence accumulate in the extracellular medium. Calcium carbonate can be produced by two different pathways: passive or active. The nitrogen cycle, including ammonification of amino-acids, degradation of urea and uric acid and dissimilatory reduction of nitrates, contributes to passive calcium carbonate formation. Ureolytic bacteria can hydrolyze urea producing ammonia and $\mathrm{CO}_{2}$. The high $\mathrm{pH}$ around the cells in the presence of available $\mathrm{CO}_{2}$ and calcium ions allows calcium carbonate precipitation. The sulfur cycle also contributes to passive calcium carbonate precipitation by dissimilatory reduction of sulfates. In active calcium carbonate production the mechanism is not clear but is probably initiated by ion exchange through the cell membrane, by activation of calcium and/or magnesium ion pumps or channels, probably coupled with carbonate ion production (2).

Our research group in Brazil is working on biodeterioration and biocalcification of building materials. One of the initial investigations centered round tests of culture media and crystal formation by different strains of bacteria. We investigated biocalcification by bacterial strains from the Brazilian Culture Collection of the Instituto Nacional de Controle de Qualidade em Saúde (INCQS) in two culture media in order to select the best conditions for subsequent application to fiber cement roof tiles.

\section{MATERIALS AND METHODS}

\section{Microorganisms}

Seven strains from the Brazilian Culture Collection of the Instituto Nacional de Controle de Qualidade em Saúde (INQCSS) of the Fundação Oswaldo Cruz were initially tested by qualitative tests; three of them gave good results and were selected for quantitative testing: Lysinibacillus sphaericus INQCS 414 (ATCC - American Type Culture Collection 14577), Bacillus subtilis INQCS 328 (ATCC 23856) and Pseudomonas putida INQCS 113 (ATCC 15175).

\section{Culture media}

Two culture media were tested: modified B4 medium (16) without $\mathrm{pH}$ adjustment, containing yeast extract $1 \mathrm{~g}$ (Acumedia), glucose 1g ( Synth), calcium acetate monohydrate $5 \mathrm{~g}$ (Synth) per 1 liter of deionized water, and a liquid culture medium called "295" by the Bacteria Collection of Laboratorium voor Microbiologie, Universiteit Gent $\mathrm{BCCM}^{\mathrm{TM}} / \mathrm{LMG}$ and utilized by Dick et al. (6), containing nutrient broth 3g (Oxoid), sodium bicarbonate 12g (Synth), urea $10 \mathrm{~g}$ (Synth) and calcium chloride dehydrate $7.5 \mathrm{~g}$ (Synth) in 1 liter of deionized water. Apart from urea, the culture media were sterilized at $120^{\circ} \mathrm{C}$ for 20 minutes. Urea was sterilized by membrane filtration $(0.22 \mu \mathrm{m})$ and added afterwards.

\section{Sample preparation}

$25 \mathrm{ml}$ of each culture medium was inoculated with $250 \mu \mathrm{l}$ 
of an overnight culture of each strain grown in 295 medium without calcium. Negative controls were not inoculated. All tests were carried out in triplicate. Incubation was at $28^{\circ} \mathrm{C}$, cultures and controls were either static or shaken at $100 \mathrm{rpm}$ for 12 days. After this period of incubation, inoculated media and sterile controls were vacuum filtered using Whatman glass fiber filters GF/C (1.2 $\mu \mathrm{m})$. Filtered medium was transferred quantitatively to a $500 \mathrm{ml}$ volumetric balloon flask. This solution was acidified with nitric acid to dissolve the calcium completely. For B4 medium, calcium carbonate was identified by X-ray powder diffraction analysis (XRD) and examined by environmental scanning electron microscopy (ESEM). Calcium ion remaining in the culture media after bacterial growth was measured using atomic absorption spectrometry as an indication of calcium carbonate content.

\section{Calcium ion analysis by atomic absorption spectrometry}

Calcium ion was determined by atomic absorption spectrometry in a Varian Spectra A 55 model, with SIPS dilutor. The following reading parameters were adopted: Current 10mA lamp, acetylene-reducing nitrous oxide flame, wavelength $239.9 \mathrm{~nm}$, slit $0.2 \mathrm{~mm}$, range $25 \mathrm{ppm}$ to $500 \mathrm{ppm}$. A calcium standard (1000ppm), Buck brand, Lot \# 9912L was used.

\section{X-ray powder diffraction analysis (XRD)}

X-ray powder diffraction analysis was carried out in a Bragg-Brentano diffractometer (Panalytical X'Pert Pro) with a fine long focus $\mathrm{CuK} \alpha$ tube anode, applying $45 \mathrm{KV} / 40 \mathrm{~mA}$. The detector used was the $X^{\prime}$ Celerator, a multiple strip position sensitive detector that allows measurement in a shorter time than a point detector. The scans were obtained from 3 to $70^{\circ} 2 \theta$ with a step size of $0.017^{\circ} 2 \theta$ with 20 s of time/step.

\section{Environmental Scanning Electron Microcopy (ESEM)}

Precipitation in shaken and static B4 medium was visualized by environmental scanning electron microscopy. All other culture parameters were the same as described above.
The liquid medium was centrifuged at $5000 \mathrm{rpm}$ and sediment re-suspended in $0.5 \mathrm{~mL}$, dried on a glass slide at $40^{\circ} \mathrm{C}$ for $48 \mathrm{~h}$ and maintained in a sterile Petri dish until ESEM analysis. The drying procedure did not alter the size and shape of calcium carbonate crystals. ESEM was carried out in a Quanta 600 FEG (FEI) microscope with a pressure of $400 \mathrm{~Pa}$, using a back scattering GAD detector.

\section{RESULTS AND DISCUSSION}

\section{Calcium ion quantification in liquid culture media}

As shown in Figure 1, modified B4 showed a greater decrease in calcium ions than 295, for all strains tested, indicating that more calcium carbonate was produced in the former medium. Medium 295 has been used successfully for testing different ureolytic bacteria of the Bacillus genus (6), but it did not prove useful for the bacteria used in our study; modified B4 (20) gave greater calcium carbonate bioprecipitation. In modified B4, Pseudomonas putida consumed on average $96 \%$, Lysinibacillus sphaericus $74 \%$ and Bacillus subtilis $28 \%$ calcium ion compared to the negative control without bacteria.

Although this Pseudomonas putida INQCS 113 has been shown to possess urease activity, the lack of urea in modified B4 medium indicates that the calcium carbonate precipitation induced by this strain is not necessarily related to urea degradation. In 295 medium, which contain $10 \mathrm{gL}^{-1}$ of urea, calcium carbonate precipitation by $P$. putida was not increased.

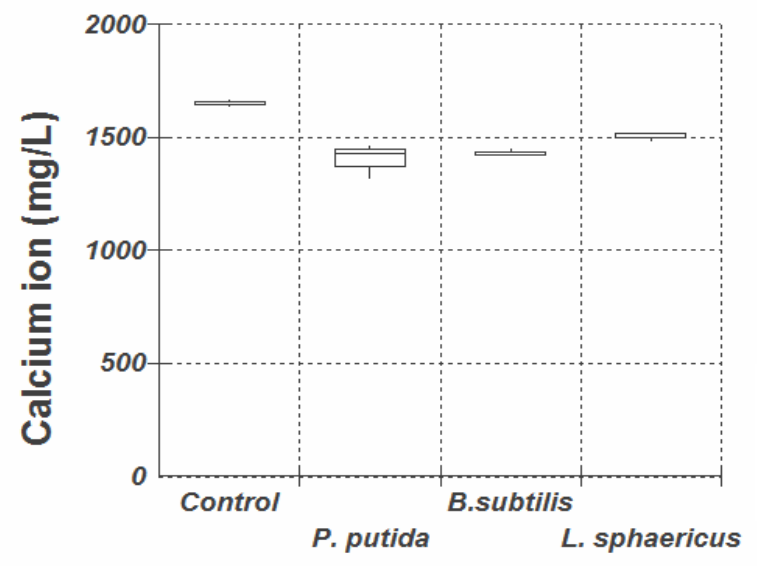

a) 


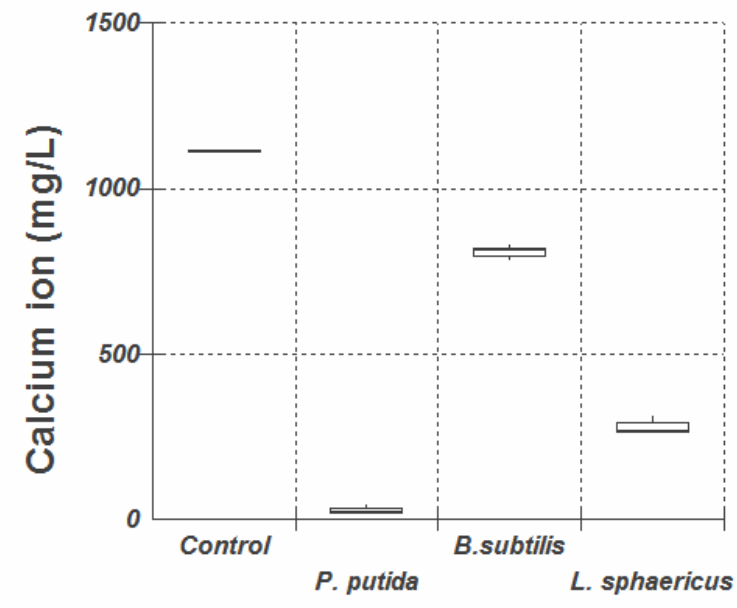

Figure 1. Median, quartiles and maximum and minimum value of remaining concentration of calcium ion $(\mathrm{mg} / \mathrm{l}) 12$ days incubation at $28^{\circ} \mathrm{C}$, in (a) medium 295 and in (b) modified B4 culture medium.

\section{Calcium carbonate characterization by XRD analysis}

Since medium 295 did not show high calcium ion consumption, ESEM and XRD analyses were carried out only on modified B4 medium.

XRD analysis (Figure 2) showed that Pseudomonas putida
INQCS 113 and Bacillus subtilis INQCS 328 produced calcite and vaterite, while Lysinibacillus sphaericus INQCS 414 produced only vaterite in shaken cultures. It is well-known that vaterite transforms into calcite on simple contact with water at room temperature (Nassrallah-Aboukaïs et al., 2003). The association of calcite and vaterite in Pseudomonas putida INQCS 113 and Bacillus subtilis INQCS 328 cultures could be due to this effect.

Our preliminary study showed that calcium carbonate crystals may vary depending on other components of the media; for example, in B4 agar calcite was produced by B.sphaericus INQCS 414. The reason for this is not yet clear. Although $P$. putida produced calcite, it is obvious from Figure 2(a) that the intensity of the calcite phase at the $29.372 \theta$ degree main peak is lower than the vaterite phase; we have also found in another study that this strain precipitates only calcite on cementitious surfaces in this culture medium. Bacillus subtilis produced calcite and vaterite and the main peak of calcite was as high as vaterite (Fig 2-c). Figure 3 shows the comparison of XRD patterns of the three strains in relation to the control without bacteria with no crystallization.

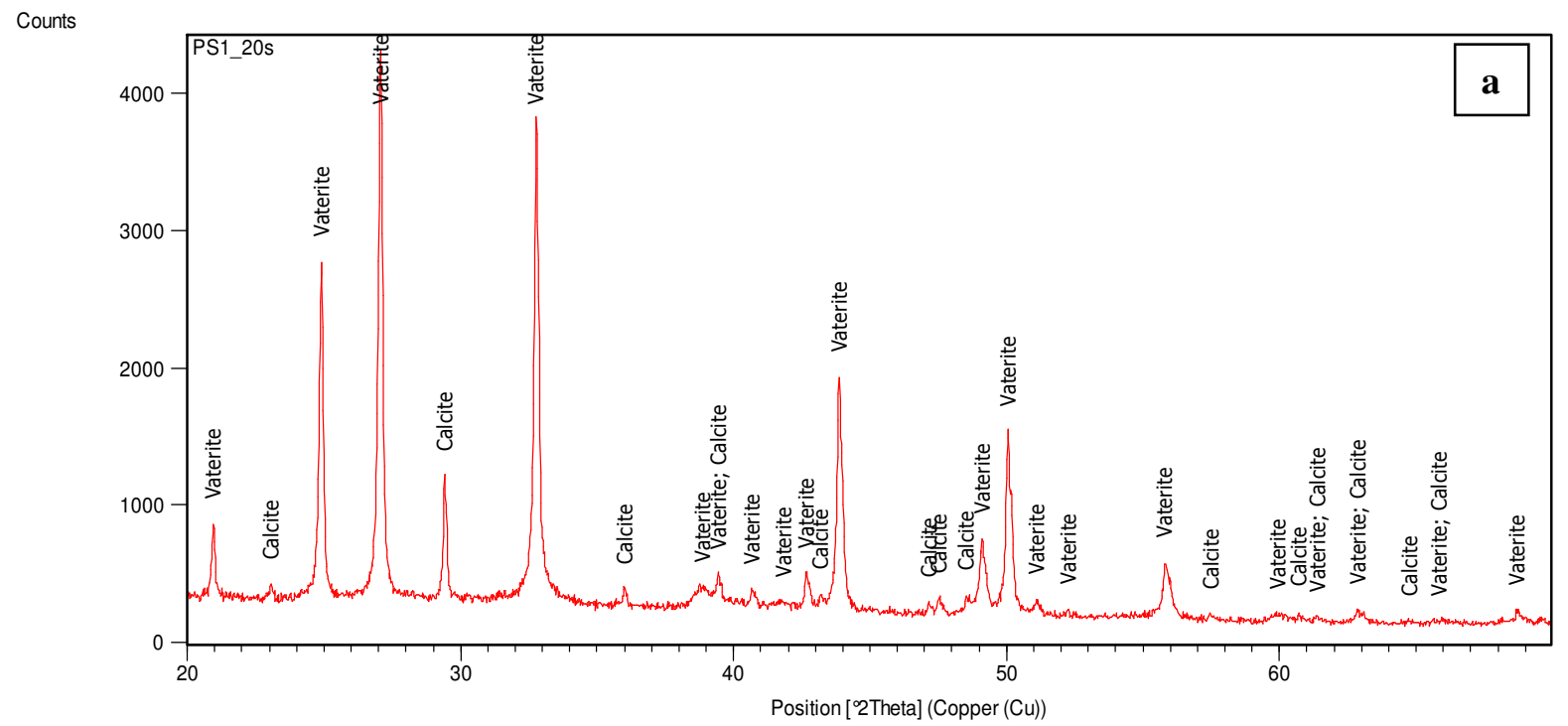



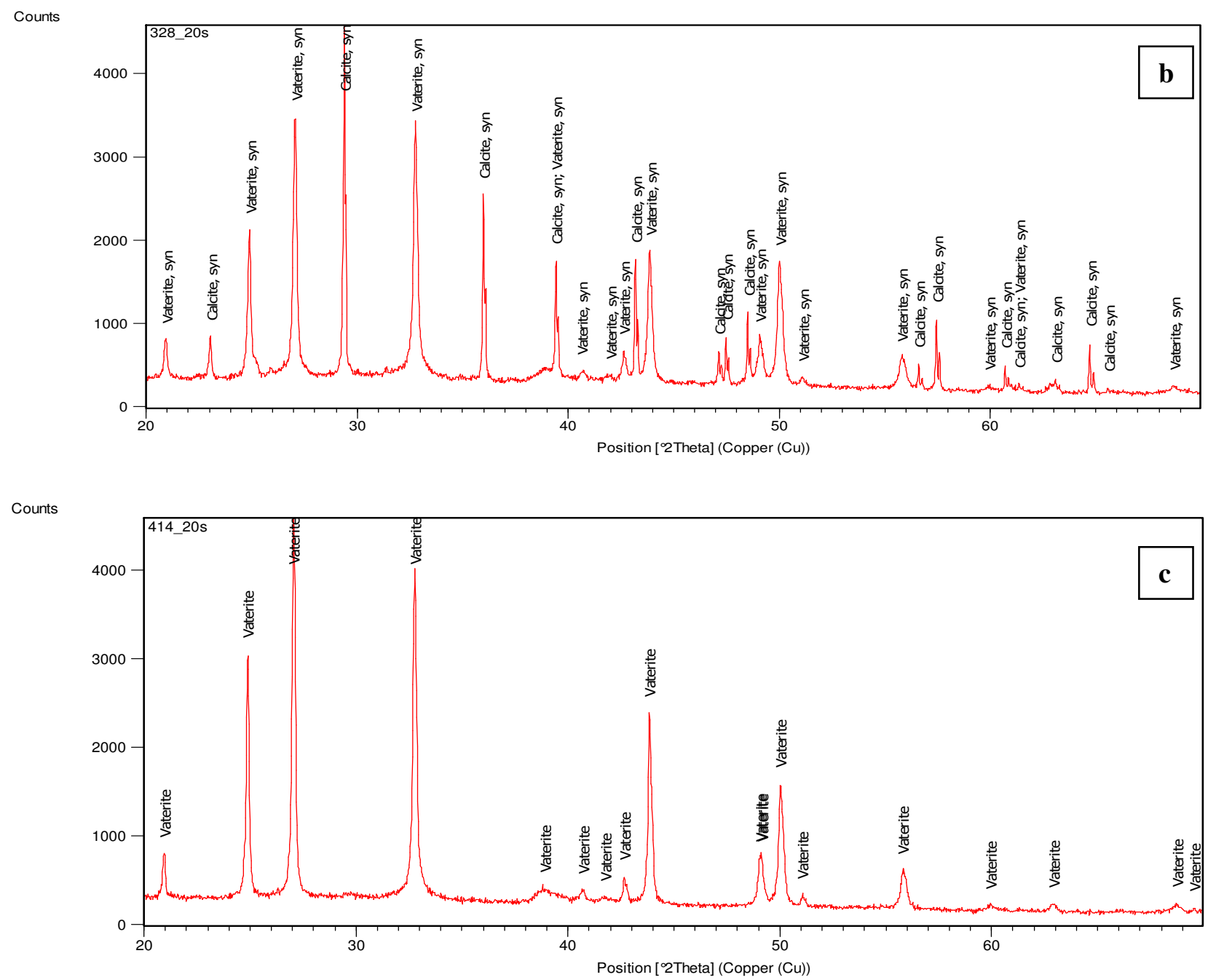

Figure 2. XRD analysis of cultures after 12 days incubation in modified B4 medium at $100 \mathrm{rpm}$. Pseudomonas putida INQCS 113 (a) and Bacillus subtilis INQCS 328 (b) favored the precipitation of calcite and vaterite. Lysinibacillus sphaericus INQCS 414 prepitated only vaterite (c).

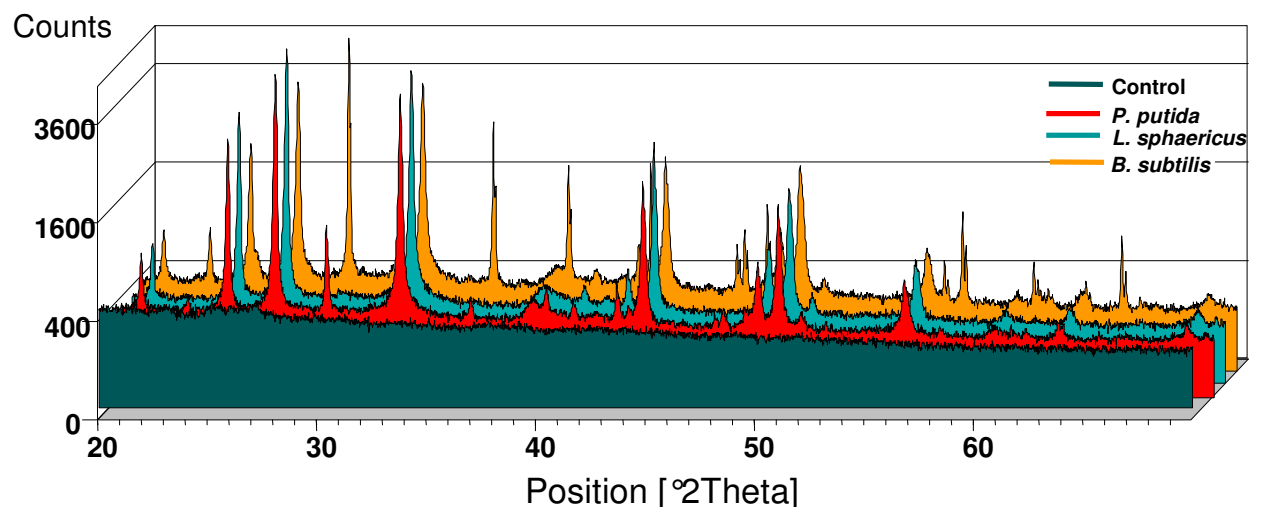

Figure 3. XRD Patterns comparing control without bacterial inoculation in the front plane without crystals, followed by Pseudomonas putida INQCS 113, Lysinibacillus sphaericus INQCS 414 (3) and Bacillus subitilis INQCS 328. 
Calcium carbonate characterization by Environmental

\section{Scanning Electron Microscopy (ESEM)}

ESEM images for all strains in B4 medium showed that static conditions produced larger calcium carbonate crystals than in shaken cultures.

$P$. putida incubation in shaken B4 favored the formation of spherical forms of calcium carbonate crystals (Figure 4), the larger ones having a diameter around $20 \mu \mathrm{m}$. For the static culture (Figure 5) other forms were also observed, rhombohedral and pinacoid crystals, sometimes with a pseudooctahedral form, larger than $100 \mu \mathrm{m}$.
Bacillus subtilis incubated in B4 medium in the shaker (Figure 6) produced spherical crystals and others identical to those observed in Figure 5b; in this case the maximum size was around 20 to $30 \mu \mathrm{m}$. Calcium carbonate crystals produced under static conditions in the presence of Lysinibacillus sphaericus were larger than in shaken cultures (Figures 7 and 8). It is clearly observed at higher magnification that cells of both Bacillus species served as nucleation sites for the spherical crystals; holes corresponding to the cell size can be seen in the crystals.
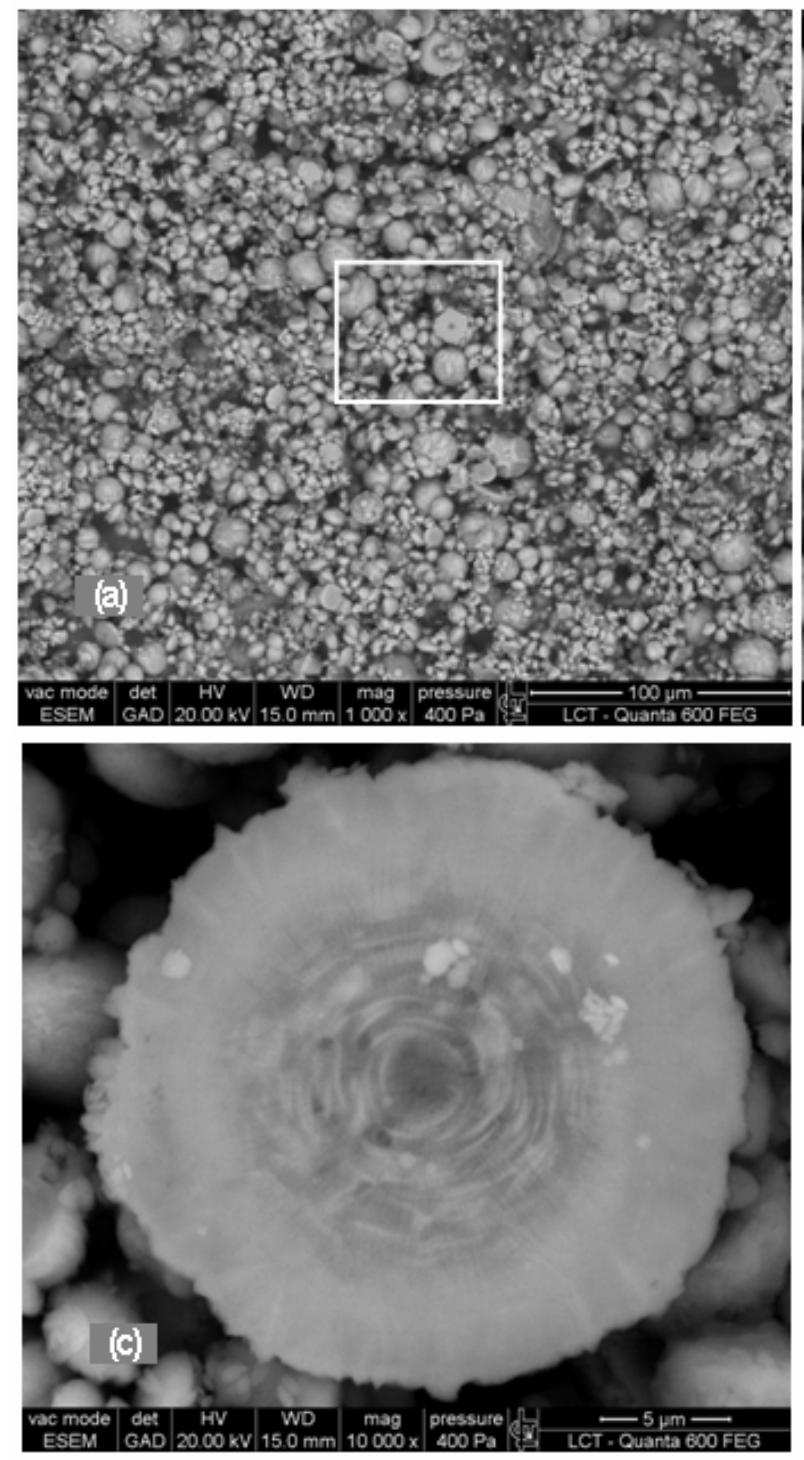

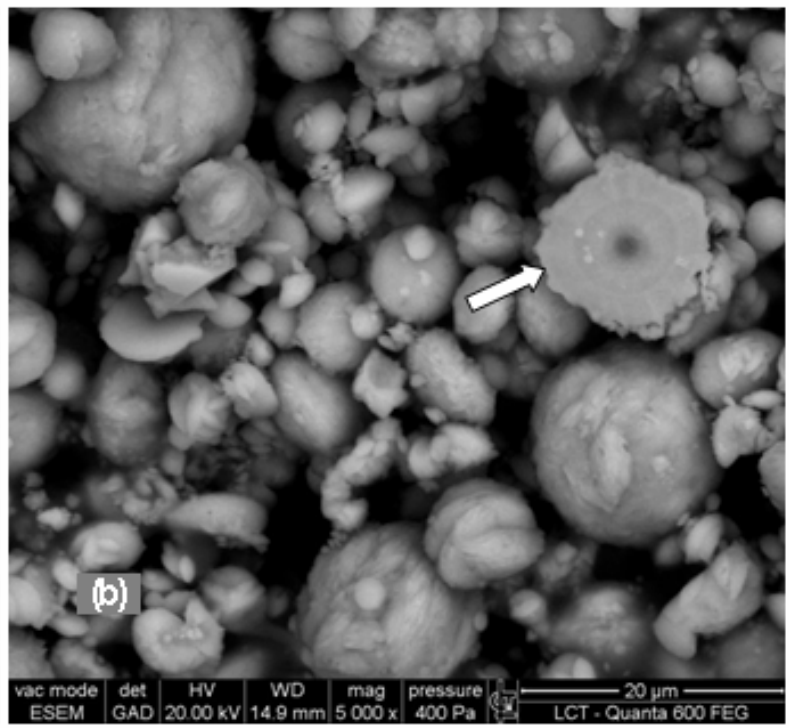

Figure 4. Environmental scanning electron micrograph of different forms of calcium carbonate crystals produced in modified B4 medium after 12 days incubation at $28^{\circ} \mathrm{C}$ inoculated with Pseudomonas putida INQCS 113 in shaker at 100 rotations per minute. (a) $\mathrm{CaCO}_{3}$ particles at low magnification; (b) the rectangle shown in (a) at higher magnification; (c) hemi-spherical particle arrowed in (b), probably produced on the glass wall. 

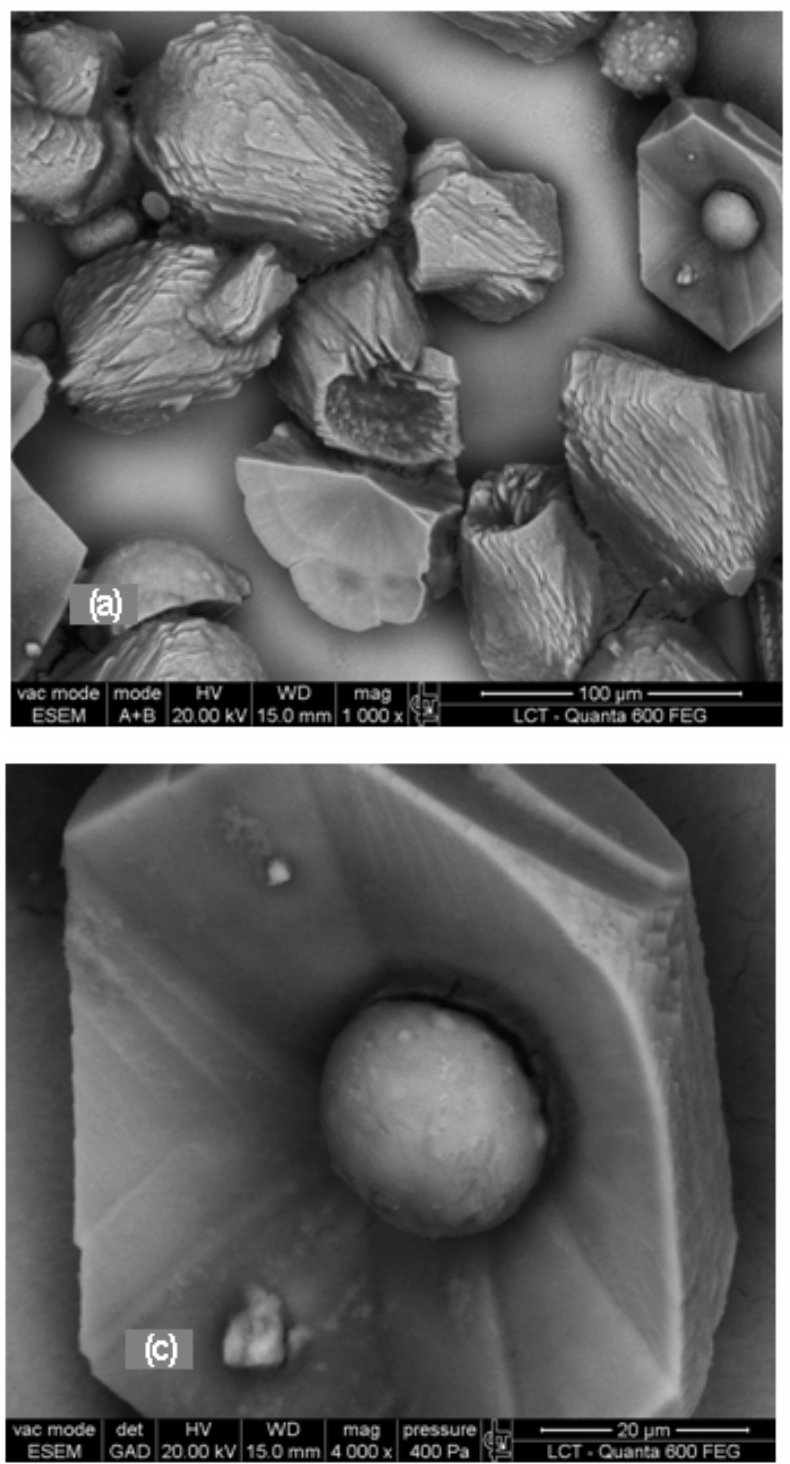

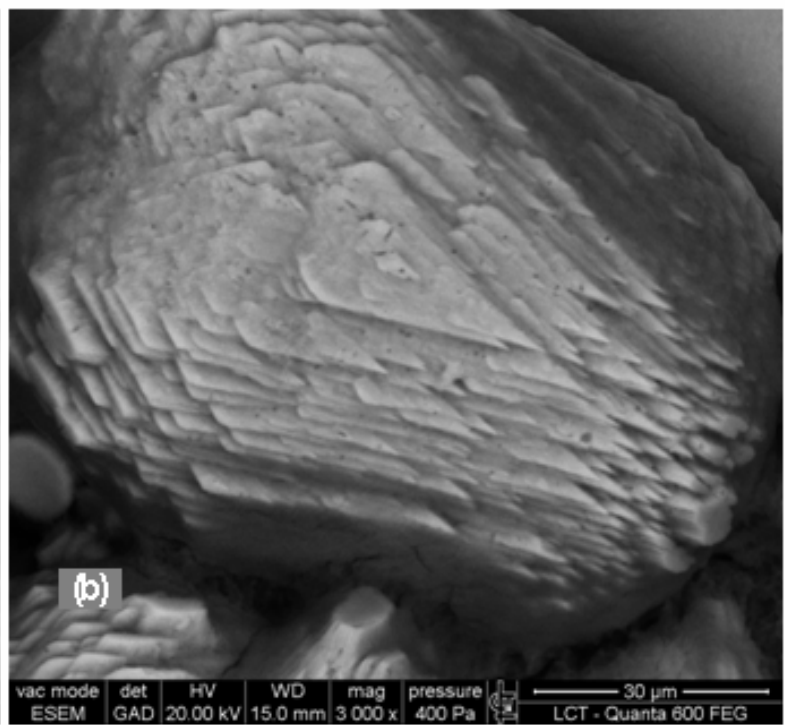

Figure 5. Environmental scanning electron micrograph of different forms of calcium carbonate crystals produced in modified B4 medium after 12 days incubation at $28^{\circ} \mathrm{C}$ inoculated with Pseudomonas putida INQCS 113 in static conditions. (a) calcium carbonate particles at low magnification; (b) higher magnification of a crystal from (a) showing rhombohedral and pinacoidal faces; (c) spherical calcium carbonate within a rhombohedral and pinacoidal crystal.

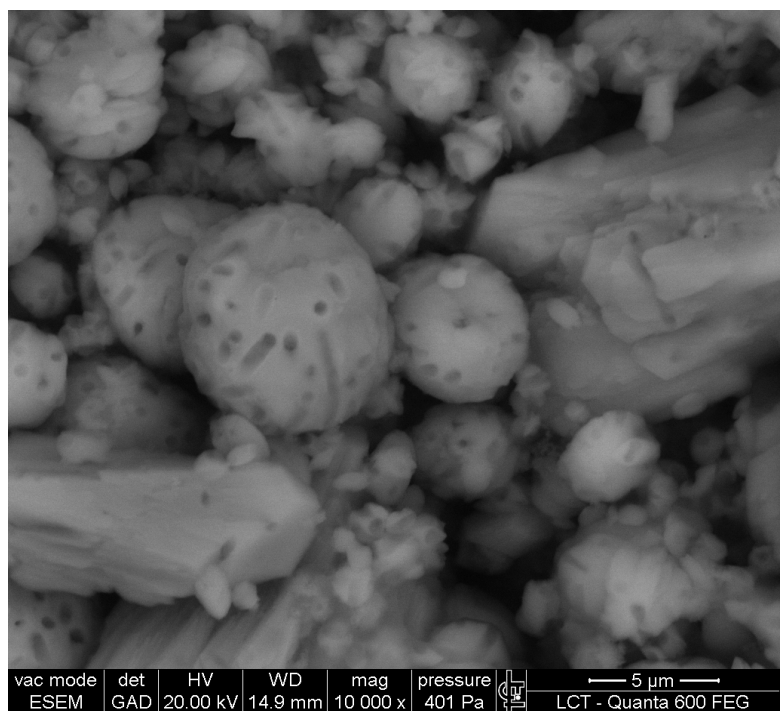

Figure 6. Environmental scanning electron micrograph of calcium carbonate crystals produced in modified B4 medium after 12 days incubation at $28^{\circ} \mathrm{C}$ with Bacillus subtilis INQCS 328 in shaker at 100 rotations per minute. 


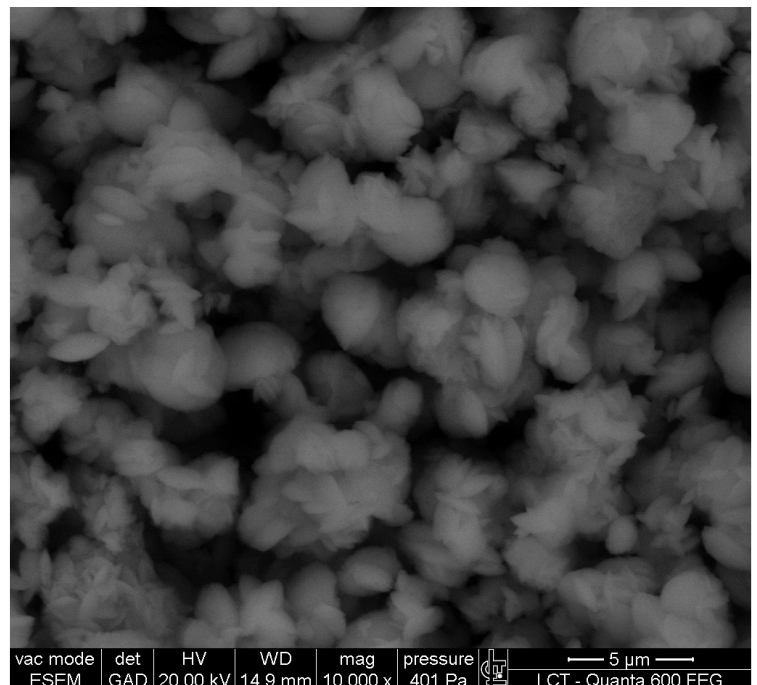

Figure 7. Environmental scanning electron micrograph of different forms of calcium carbonate crystals produced in modified B4 medium after 12 days incubation at $28^{\circ} \mathrm{C}$ with Lysinibacillus sphaericus INQCS 414 in shaker at 100 rotations per minute.

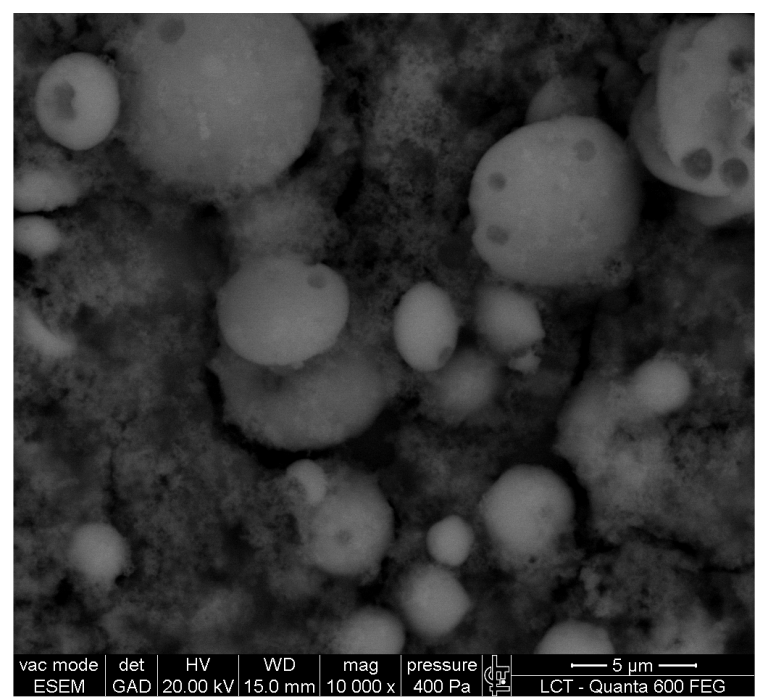

Figure 8. Environmental scanning electron micrograph of calcium carbonate crystals produced in modified B4 medium after 12 days incubation at $28^{\circ} \mathrm{C}$ with Lysinibacillus sphaericus INQCS 414 in static conditions.

Previous studies showed that the composition of the culture medium, $\mathrm{pH}$, and salinity can change the type of crystals produced $(14,16)$. Recently Zamarreňo et al (23) observed that the temperature of incubation can affect the concentration of calcium carbonate and the polymorphs. However this is the first time that shaking, at the same temperature in a given medium, has been shown to change the size and shape of crystals produced by biocalcification.

\section{CONCLUSIONS}

Culture medium had a large impact on calcium carbonate bioprecipitation. In this study modified B4 culture medium was better for calcium carbonate precipitation than 295 for all strains tested. Even the ureolytic $P$. putida INQCS 113 did not respond better on the urea-containing medium 295. In modified B4 medium Pseudomonas putida INQCS 113 gave the highest calcium carbonate precipitation, consuming on average $96 \%$ calcium ions from the medium, followed by Lysinibacillus sphaericus INQCS 414 (74\%). Bacillus subtilis INQCS 328 gave only $28 \%$. The shape and size of the crystals are affected by culture medium, bacterial strain and incubation conditions, static or shaken. $P$. putida INQCS 113 in modified B4 medium showed the highest efficiency. In the next step of this research, $P$. putida INQCS 113 in B4 will be applied to industrial fiber cement and the ability of the resulting biocalcification to improve durability will be evaluated by measuring water absorption.

\section{ACKNOWLEGDMENT}

Fundação de Amparo à Pesquisa do Estado de São Paulo FAPESP - for sponsoring this research (Processo 2006/568604) and for the grant to MA Shirakawa. CNPq for the grant to VM John and M.A Cincotto. Instituto Nacional de Controle de Qualidade em Saúde da Fundação Oswaldo Cruz is thanked for providing the bacterial strains. We also would like to thank Ana Carla Thomaz dos Santos for technical support and Fabiano Chotoli (Instituto de Pesquisas Tecnológicas de São Paulo) for suggestions on calcium analysis. 


\section{REFERENCES}

1. Boquet, E.; Boronat, A.; Ramos-Cormenzana, A. (1973). Production of calcite crystals by soil bacteria is a general phenomenon. Nature 246:527-528.

2. Castanier, S.; Le Métayer-Levrel, G.; Perthuisot J. P. (1999). Cacarbonates precipitation and limestone genesis-the microbiogeologist point of view. Sediment. Geol. 126:9-23.

3. De Jong, J.T.; Mortensen, B.M.; Martinez, B. C.; Nelson, D.C. (2010), Bio-mediated soil improvement. Ecol. Eng. 36(2): 197-210.

4. De Muynck, W.; Cox, K.; De Belie N.; Verstraete, W. (2008). Bacterial carbonate precipitation as an alternative treatment for concrete. Constr. Build. Mater. 22(5): 875-885.

5. De Muynck, W.; De Belie, N.; Verstraete, W. (2010). Microbial carbonate precipitation in construction materials: A review. Ecol. Eng. 36(2): 118-136.

6. Dick, J.; De Windt, W.; De Graef, B.; Saveyn, H.; Van der Meeren, P; De Belie, N.; Verstraete, W. (2006). Bio-deposition of a calcium carbonate layer on degraded limestone by Bacillus species. Biodegradation 17(4): 357-367.

7. Ercole, C.; Cachio, P.; Botta, A.L.; Centi, V.; Ledipi, A. (2007) Bacterially induced mineralization of calcium carbonate: the role of exopolysaccharides and capsular polysaccharides. Microsc. Mycroanal. 13 (1): 42-50.

8. Le Métayer-Levrel, G; Castanier, S.; Orial,G.; Loubière, J.F.; Perthuisot; J.P. (1999). Applications of bacterial carbonatogenesis to protection and regeneration of limestones in buildings and historic patrimony. Sediment. Geol. 126: 25-34.

9. Lowenstam, H.A. (1981). Minerals formed by organisms. Science
211:1126-31.

10. Nassrallah-Aboukaïs, ; Jacquemin, J.; Decarne, C.; Abi-Aad, E.; Lamonier, J.F.; Aboukaïs, A. (2003). Transfornation of vaterite into calcite in the absence and presence of copper (II) species. J. Thermal Analysis and Calorimetry. 74: 21-27.

11. Ramachandran, S.K.; Ramakrishnan, V.; Bang, S.S. (2001). Remediation of concrete using microorganisms. A C.I. Mater. J. 98: 3-9.

12. Rivadeneyra M.A.; Delgado G.; Soriano M.; Ramos-Cormenzana, A.; Delgado, R. (2000). Precipitation of carbonates by Nesterenkonia halobia in liquid media. Chemosphere 41: 617-624.

13. Sánches-Román, M.; Rivadeneyra, M.A.; Vasconcelos, C.; McKenzie, J. A. (2007). Biomineralization of carbonate and phosphate by moderately halophilic bacteria. FEMS Microbiol. Ecol. 61:273-284.

14. Stocks-Fischer, S.; Galinat, J.K.; Bang, S. (1999). Microbiological precipitation of $\mathrm{CaCO}_{3}$. Soil Biol. Biochem. 31:1563-1571.

15. Webster, A.; May, E. (2006). Bioremediation of weathered-building stone surfaces. Trends Biotechnol. 24(6): 255-260.

16. Webster, A. M, Vicente,D., May, E. (2004). Bacteria and bioremediation of stone: The potential for saving cultural heritage. European Symposium in Environmental Biotechnology, Oostende. Available at: http://www.biobrush.org/Dissemination/Ostend\%20paper.pdf. Accessed 05 June 2009.

17. Whiffin, V.S.; Van Paassen, L.A.; Harkes, M.P. (2007). Microbial carbonate precipitation as a soil improvement technique. Geomicrobiol. J. 24 (5): 417-423.

18. Xu, A-W.; Ma, Y.; Cölfen, H. (2007). Biomimetic mineralization. J. Mater. Chem. 17: 415-449.

19. Zamarreňo, Dania V., Eric May and Robert Inkpen. 2009. Influence of Environmental Temperature on Biocalcification by Non-sporing Freshwater Bacteria. Geomicrobiol. J. 26(4):298-309. 